\title{
TURN-TAKING AND GENDER DOMINANCE ISSUE
}

\author{
Instructor: Amani M. Hussein(M.A.) \\ College of Education / Ibn Rushd \\ University of Baghdad
}

DOI: $10.37648 /$ ijrssh.v10i02.015

Received:05 $5^{\text {th }}$ January, 2020; Accepted:12 $2^{\text {th }}$ February, 2020; Published: $12^{\text {th }}$ February, 2020

\begin{abstract}
When interlocutors are engaged in a talk with no conventionalized order, they indulge themselves in a conversation which means non-interrupted and non-simultaneous activity. This activity is called turn-taking which means the manner in which orderly conversation takes place.Though not all cultures' turn systems are the same, Celce-Murcia and Olshtain (2000) point out that there are often important cultural and sub-cultural differences in the way discourse communities do turn-taking.

According to Pennebaker, J. W. (2007:27-33), male interlocutors consistently interrupt females and lean to dominate conversations, regardless of community, and women's role in turn taking is frequently ignored, to a certain extent, in conversations.

The aim of the present paper is to show that females have more curiosity to take turn in conversations than men do, and they break the rule of turn- taking, because, very often, they speak simultaneously. By adopting Have's (1999) strategies of turn-taking, two tables have been provided. The first one is to show the frequencies of violations committed by men and women during the course of conversation. The second one is dedicated to show the frequencies of violations of Have's strategies by men and women. By analyzing six different episodes in which men and women have engaged in speech, the paper has concluded that women are more dominant in conversations for different reasons mainly because they do not wait for their turns.
\end{abstract}

Key words: conversation, gender, interlocutor, turn- Taking.

\section{INTRODUCTION}

Turn-taking is a term for the way in which conversation takes place. It is an arrangement of conversation and discourse in which participants speak simultaneously in orderly turns. Practically speaking, it involves processes for managing contributions, responding to previous comments, or transferring the turns to different speakers.

According to Sacks, Schegloff and Jefferson (1974) the conversational turns are unpredictable; our utterances, our actions and the order in which we say or do things cannot be determined in advance. In this account, very little of our utterances is predictable (Sindell, 2010:78). In this case, some sorts of violations may occur as there are no previous arrangements for the conversation. When an interrupter prevents the speaker from finishing their turn, it is viewed as a turn-taking violation (Coates, 2004: 111).

By the same token, when a participant takes somehow a long time on the floor and disregards others trying to take the floor, it is called "hogging the floor". Selfselectionis thecase in which multiple people begin talking simultaneously, and one person dominates and selects himself or herself as the next speaker. Overlapis the case when the next speaker overlaps the first 
speaker's turn; an anticipation before the speaker is finished. The first speaker is still capable of finishing their turn with the overlap (Coates, 2004: 113-22). Conversation is an activity in which one person speaks while another listens. Analysists interested in analyzing discourse and conversation noted that speakers have a systematic order for determining when one person's turn is over and the next participant's turn starts. Such an exchange of turns or so called 'floors' is identified by some linguistic means as intonation, pausing, and phrasing. Some interlocutors await a clear pause before starting to speak, while others have the sense that repeating the same idea can be interpreted as giving the floor to some one else (Sindell,2010 99). But when those speakers have different assumptions on the way turns exchanges are identified, they may subconsciously interrupt or feel interrupted. Likewise, speakers too, from time to time, assume the floor even though they are aware that the participants have not given them the chance to take the floor.

Undoubtedly, overlapping in turn-taking could lead to a problem facing those involved in speaking. Jefferson cited in (Heritage,1984: 105-106) proposed a categorization of overlaps in conversation, namely:

1.Transitional overlap occurs when an interlocutor enters the conversation at the possible point of completion. This happens usually when speakers take part in the conversation enthusiastically and exchange speeches with continuity.

2.Recognitional overlap takes place when a speaker speculates the possible compliment of an unfinished sentence, and tries to finish it for the present speaker. In other words, the overlap occurs as the current speaker endeavours to finish the sentence, when the other speaker simultaneously "thinks aloud" to show his understanding of the ongoing speech.

3.Progressional overlap arises as a result of the speech discontinuity of the previous speaker when another speaker self-selects to continue with the ongoing speech. For instance, when a speaker is retrieving a suitable word to utter and other speakers make use of this gap to start the turn.
Customarily, researchers have the idea that turn-taking strategies vary according to gender, therefore, turntaking has been a pivotal issue of intense rendering in gender studies (Holmes, 1992:87). Men follow a speech style based on power and try to dominate the conversation. On the other hand, early studies stood by gendered stereotypes, like men interrupting is more than women, recent research, however, has found mixed evidence of gender-specific conversational strategies, and few overarching patterns have emerged (Lerner,2004:105). Within the frame of sociolinguistic context, it is argued that because men, supposedly, are dominant in social settings, therefore, women may be expected to be more silent; so when women talk it is perceived as a manner of being talkative. Research shows that rank holds less power than gender in conversation dominance: men dominate conversation more than women (Ibid.:106).

One of the main differences between women and men's speech can be attributed to the fact that men have been found to dominate exchanges through the use of interruptions and overlaps, and that the amount of such exchanges leads to conversational irregularities; a matter which leads to interruption particularly when men are talking to women. Therefore, we can say that women are more likely than men to be subject to interruption, by members of opposite sex, in particular. Men who break the rule, they do so by interrupting the women in a group far more than they are interrupting each other. (Eckert and Mc Cornell,2003:175).

Have(1999: 88) states that men are more likely to interrupt women and women are reluctant to interrupt men.

In a research done by De Francisco (1977); Coats (1998: 120-121) who analyzed the daily speech of seven couples, arrived to the conclusion that females have more curiosity to take turn in exchanges while men stick to their own point of view or remain silent, and finally reject the offer to take the floor.

\section{WHAT IS TURN -TAKING?}

A turn is the time when a speaker is talking and turntaking is the skill of knowing when to start and when to finish a turn in a conversation. That is to say, the turn is part of the structural organization of the conversation, and what is said is part of the interactional together with 
the pragmatic strategies adopted by the speakers to make the listeners understand their intention (Lerner, 2004:5658).

According to Enfield and Stivers (2007: 134) turntakings are one way that shows how conversation is structured. They stated that "the structure of talk allows complete strangers to enter into conversations without negotiating how to go about exchanging words". On the other hand, it leaves room for strategy galore - for people to trick and foil each other, to give each other the floor or to rob each other of words.

Stenström (1994:4) defines a turn as follows "a turn is every thing the current speaker says before the next speaker takes over". Some turns are very short and consist of a single word, while other turns are very long and resemble short monologues.

Turn-taking, furthermore, can be defined as a type of an arrangement of a conversation in which interlocutors speak once at a time in exchanging turns. Practically speaking, it requires a process for showing contributions, reacting to comments previously uttered and situationing them to a different speaker, by using various linguistic and non-linguistic cues (Ibid.:6).

Accordingly, one can say that turn-taking indicates the process through which those who are indulged in a conversation choose who will speak next. On choosing a topic and initiating a conversation, the issues related to conversational turn-taking arise. An essential point lies in the fact that knowing when it is allowed or it is obligatory to take a turn in conversation is vital to the cooperative part of talk.

Generally speaking, it was the sociologists such as Harvey Sacks, Emanuel Schegloff, and Gail Jefferson who described, for the first time, the concept of turntaking through their "A Simplest Systematics for the Organization of Turn-Taking for Conversation" which appeared in the Journal of Language, 1974.

Those sociologists gave an account on how interlocutors built and distributed turns in a systematic way. Sacks et al. exerted efforts on elaborating the order of turn-taking organization in order to consider it as a model, that is based on the phenomenon of turn-taking; a model was centered on the concept of turn constructional items. They showed three possibilities which were involved in the administration and organization of turn-taking system:
First, a current speaker might 'self-select' which means that he or she might select themselves and go on speaking. Second, the current speaker might introduce the next speaker. Third, the current speaker might choose another interluctant instead of choosing the next speaker. This implies that 1 . the current speaker ' $A$ ' chooses the next speaker B' who may have the opportunity to speak and avail the turn. 2. If 'A' chooses another speaker ' $C$ ' instead of ' $B$ ', this will allow speaker ' $\mathrm{C}$ to speak. Not only this, but there is also a possibility of a third interluctant that ' $A$ ' current speaker does not give the chance to other speakers to take part and continue dominating the floor.

So, it goes without saying that turn-taking is an all around process which begins with one interlocutor speaking and he/she constitutes at the time when the speaker gives up control to the next person. Now the second speaker will have the conversational floor. By the time the speaker is over, interlocutors give control back to another speaker, and in this manner they lead to creating a cycle. This turn-taking style halts when there is nothing to speak.

\section{TURN- TAKING STRATEGIES}

Speakers may use different strategies to keep the conversation going on and changing turns smoothly. Have (1999:91-93) suggests the following strategies in turn taking:

\subsection{Speak, then Ask}

If you request someone to share turn-taking you ask a direct question, so you are inviting them to take their turn.

\subsection{Use Conjunctions}

Conjunctions and connectors like however, no doubt, definitely, deadly sure, nevertheless, on the contrary or as a result, help speakers take longer turns.

\subsection{Phrases for Agreeing $\backslash$ Disagreeing}

To agree or to disagree with what is being said is one of the great ways to keep the conversation going on.

Here are some phrases you can use:

- I agree/disagree with you. 
- I'm afraid I can't/don't agree with you.

- I couldn't agree more.

- Of course.

- Absolutely.

- No doubt

- A hundred percent.

\section{Phrasesfor Asking for/Giving Opinions}

It goes without saying that like the above mentioned skill, it is significant for speakers to be capable of not only expressing their opinions, but also asking others for their own. Some of the phrases that a speaker can make use of are:

- Do you like that idea?

- What do you think?

- Does that make sense to you?

- How far is the idea applicable?

- Is it true?

\section{FillersforPauses}

Speakers tend to fill in their phrases with some fillers. These fillers generally include :

- Let me see...

- Let me think...

- The thing is...

- What I mean is...

- What I suppose is....

\section{TURN- TAKING CUES}

Turn cues can be summarized as follows (Lerner,2004: 115-117):

-When the present speaker asks a question, it could be a cue for another person to take over.

- If the current speaker trails off, it might be a cue for someone else to snatch the floor.

-If the speaker indicates that they are done speaking with a closing statement e.g. And so that's all..., so to speak........ .

-Marker words: but, so..., well..., in fact..., honestly speaking....

-Completion of grammatical clause.
-Intonation: pitch/loudness.

-Body motion.

- Facial expressions.

-Pondering.

- Shrugging.

\section{RESEARCH METHODOLOGY}

The data of the present paper were collected, randomly, from different channels. The first three episodes were taken from mbc4 TV programs; namely, "The Drs", ,Dr. Phil" and "The Talk". The fourth one was taken from Al-Hurra T.V. The last two were taken from Al-Iraqia T.V. A 60 -minute episode was taken from each program. The conversation is male to female so that the paper can find out which one of both genders is dominant in the conversation and thus has more influence over the other in conversation.

In order to verify the credibility of the results of the conversations, a second rater was asked from a peerreviewer to score with the researcher to make sure the validity and the reliability of the results. The rate of conformity was $91 \%$.

The rater was Assist. Prof. Dr. Yousuf. J. Mohammed. E-Mail: (yousufjm44@gmail.com).

The episodes were as follows:

1."The Drs" Diet: Meat and Eggs are Slimming? Dated December 17,2015.

2.'Dr. Phil" Mcgraw Connick. Dated July 5, 2015.

3."The Talk" James Corden Interview. Dated March 21, 2016.

4. "هن "/honnə/: University Counseling as an Integral Part of Education Process. Dated January 11, 2017

5. "Noon" /noun/ : Woman and Society. Dated February 22, 2017

6. "ونطقت شهرزاد /wə nətkət Səhrəzad : Iraqi Women Status and Labour. Dated May 7, 2017

\section{DATA ANALYSIS AND RESULTS}

The analysis is based on how many times females broke the course of speech and took the floor, what were the strategies they used in order to take the turn? In other words, which of Have's strategies were chiefly used by women in dominating the course of speech? And to what extent did women follow those strategies? 
Two tables have been presented in order to enhance the analysis. Table (1) aims to show the frequency of the turns, while table (2) is devoted to show the frequency of violating the strategies used by the speakers in general.
Depending on the analysis, table (1) below shows the frequency of the turns taking by men and women of each episode of the programs:

Table (1) Frequency of turn-taking between men and women

\begin{tabular}{|l|l|l|}
\hline Name of Program & Frequency of Male Violations & $\begin{array}{l}\text { Frequency of Female } \\
\text { Violations }\end{array}$ \\
\hline The Drs. & 43 & $\mathbf{5 6}$ \\
\hline Dr. Fill. & 37 & 62 \\
\hline The Talk & 41 & 58 \\
\hline ه & 39 & 58 \\
\hline ونقت شهرزاد & 42 & 63 \\
\hline نوز & 31 & 69 \\
\hline
\end{tabular}

From the table above, which shows the frequency of violating the turns, it is clear that women, in the six programs, take more turns in conversation than men do. This means that women do not wait for their turns during the course of speech. As regards the strategies mentioned earlier, whether in terms of asking and speaking which the speaker uses to give the floor to the next speaker, or the use of the conjunctions, such as, however, as a result, which give the speaker the opportunity to remain holding the floor, and so on. Contrary to what has been mentioned earlier, women try to seize the opportunity to dominate the floor.

It goes without saying that when women speak, they do not take into consideration neither the strategies nor the cues of turn-taking. They usually express themselves at the time they decide to speak. In other words, they do not follow the principles of the turns. From table (1) above, women break the rule of the discourse and interrupted men much more than men do.

Table (2) below shows the frequencies of the violations committed by men and women in not following the strategies of turn-taking. For instance, the first and the second strategies which the speaker manipulates to give the turn to the next speaker, but women are still holding the floor.

The same case of violation is evident with the other strategies; women are more curious in either holding the floor for a long time or in interrupting men. Sometimes, women interrupt each other or one of them holds the floor for a long time ignoring all the strategies that the latter speaker adopts.

Table (2) Frequency of strategies used in turn-taking

\begin{tabular}{|l|l|l|}
\hline Name of the strategies violation & $\begin{array}{l}\text { Frequencyof } \\
\text { committed by women }\end{array}$ \\
\hline Speak then ask & 16 & 43 \\
\hline Use of conjunctions & 28 & 58 \\
\hline $\begin{array}{l}\text { Phrases of agreeing and } \\
\text { disagreeing }\end{array}$ & 14 & 25 \\
\hline $\begin{array}{l}\text { Phrases for asking for/giving } \\
\text { opinions }\end{array}$ & 17 & 35 \\
\hline Fillers for pauses & 21 & 37 \\
\hline
\end{tabular}


It is worth mentioning that the model of the strategies set by Have is inapplicable to the present analysis because women do not pay attention to Have's strategies. Contrary to the rules of turn-taking stipulated by Have's strategies, women, at many times, use the strategies to help them keep the turn not to let the turn move smoothly to a next speaker. For instance, the fourth strategy which the speaker uses to ask for the opinions of the next speakers, women use this strategy in a way to keep the turn by giving their opinions immediately without giving a chance to other speakers.

Indeed, women are fond of using fillers, as the above table shows, because they help them dominate the floor.

\section{CONCLUSION}

The present paper concludes that, in a male to female conversation, females' turn- taking rates are higher than those of the males, regardless of the community. Furthermore, the paper refers to what is taken for granted that women somehow always try to dominate the floor as shown in tables (1)\&(2). This shows gender difference in mixed gender conversations. The findings are in line with the assertions of Victoria De Francisco who has found that females have more curiosity to take turn in conversations, while men stick to their own point, remain silent, and reject the offer of turn-taking. This supports the assumption that women are more dominant than men, in this respect.

\section{REFERENCES}

Celce-Murcia, G. and Olshtain, S. (2000). Language, Culture and Society. England: Longman.

Coates, J. (Ed.). (1998). Language and gender: A reader. London: Blackwell Publishing.

(2004). Women, men, and language: A sociolinguistic account of gender differences in language. Pearson Education.

De Francisco, V. (1997). Gender, power and practice: Gender and Discourse. London: Sage.
Enfield, N. J. and Stivers, T. (2007). Person Reference in Interaction: Linguistic, Cultural and Social Perspectives. Cambridge: Cambridge University Press.

Eckert, J. and Mc Cornell, G, S. (2003). Language and Gender. Cambridge: Cambridge University Press..

Have, T. P. (1999): Doing Conversation Analysis. A Practical Guide. Thousand Oaks: Sage.

Heritage, J.(1984). Garfinkel and Ethnomethodology, Cambridge: PolityPress.

Holmes, J. (1992). An Introduction to Sociolinguistics. England:Longman

Lerner, G. H. (ed.) (2004) Conversation Analysis: studies from the first generation. Philadelphia: John Benjamins Publishing.

Oreström, A.B. (1994). An Introduction to Spoken Interaction. London:Longman.

Pennebaker, J. W. (2007). Are women really more talkative than men? England: Longman.

Sidnell, J. (2010). Conversation Analysis: An Introduction. London: Wiley-Blackwell. 